\title{
RANCANG BANGUN INTERNET SEHAT DI SMPN UNGGULAN INDRAMAYU MENGGUNAKAN PROXY SERVER
}

\author{
Willy Permana Putra ${ }^{1}$, A Sumarudin ${ }^{2}$, Ahmad Lubis Ghozali ${ }^{3}$, Darsih ${ }^{4}$ \\ 1,2,3 Jurusan Teknik Informatika,Politeknik Negeri Indramayu \\ E-mail : willy@polindra.ac.id, shumaru@polindra.ac.id,lubis@polindra.ac.id
}

\begin{abstract}
ABSTRAK
Perkembangan internet saat ini merupakan keniscayaan, perkembangannya menyentuh beberapa bidang dan segi kehidupan masyarakat, dimulai dari internet tingkat perguruan tinggi sampai sekolah dasar. Dalam perkembangannya memiliki dampak positif yaitu percepatan informasi berupa pengetahuan, komunikasi dan Entertainment. Tetapi juga memiliki dampak negatif berupa informasi berkonten negatif seperti pornografi, radikalisme dan terorisme yang akan berdampak serius bagi siswa SMP yang merupakan usia remaja. Oleh sebab itu, maka penerapan teknologi Proxy sebagai media penyaring konten negatif menggunakan squid. Dengan penerapan instalasi Proxy server ini didapat internet di SMPN Unggulan dapat terpantau koneksi yang terjadi dan dapat melakukan penyaringan situs yang berpotensi menyebarkan konten negatif. Selain itu pula didapat koneksi internet dengan menggunakan Proxy server juga mampu meningkatkan performa jaringan menjadi 2.3 kali lebih cepat.
\end{abstract}

\section{Kata Kunci: Internet sehat, Proxy server, siswa}

\begin{abstract}
The development of the internet at this time is a necessity, its development touches several fields and facets of community life, starting from the internet college level to elementary school. In its development has a positive impact, namely the acceleration of information in the form of knowledge, communication and entertainment. But it also has a negative impact in the form of negative content information such as pornography, radicalism and terrorism which will have a serious impact on junior high school students who are in their teens. Therefore, the application of Proxy technology as a filter media for negative content uses Squid. With the application of this Proxy server installation, it can be obtained that the internet at Featured SMPN can monitor the connections that occur and can filter sites that have the potential to spread negative content. In addition, an internet connection using a proxy server is also able to increase network performance to 2.3 times faster.
\end{abstract}

Keywords: Healthy internet, proxy server, students 


\section{PENDAHULUAN}

Perkembangan teknologi saat ini sudah semakin pesat bahkan perkembangan dari teknologi merambah ke berbagai sisi kehidupan manusia. Perkembangan yang sedemikian pesat tidak lupa didukung oleh perangkat keras dan perangkat lunak yang semakin hari semakin berkembang. Salah satu teknologi yang popular yaitu Internet.

Internet bisa dikatakan suatu perpustakaan besar di dunia maya, yang di dalamnya terdapat jutaan bahkan milyaran informasi yang terkandung di dalamnya. Salah satu contoh kelebihan dari internet adalah berisi informasi berupa teks, gambar, video, suara, dan masih banyak yang terkandung di dalamnya. Perkembangan yang pesat menjadikan internet sebagai primadona di kalangan masyarakat ini terlihat dalam aktivitas kegiatan sehari-hari seperti membuka berita, sebagai transaksi jual beli Online dan menyediakan berbagai layanan. Namun teknologi internet tidak dapat dipisahkan dari dampak positif dan negatif, dampak positif dari teknologi internet adalah bisa sebagai sarana informasi belajar maupun untuk sarana komunikasi seperti sekarang ini dan dampak negatif dari teknologi internet yaitu banyaknya berita-berita bohong dengan kata lain informasi yang tidak benar, pornografi yang mudah di akses melalui internet serta kejahatan-kejahatan yang memanfaatkan layanan internet seperti peretasan dan pencurian data. Teknologi internet memang cepat berkembang paling tidak ada batasan dalam penggunaan internet tersebut yang bisa mencegah penyalahgunaan teknologi internet, salah satu teknologi yang mungkin bisa mencegah hal semua itu yaitu dengan penerapan server Proxy.

Sekolah adalah hal mendasar yang perlu di waspadai dan perlunya bimbingan khusus supaya generasi muda bisa terselamatkan dari negatifnya teknologi internet. Banyak sekolah yang mengabaikan permasalahan ini sehingga banyak bermunculan tindakan asusila yang terjadi di sekolah, ini disebabkan kuranya pengawasan internet di sekolah. Permasalahan ini sering kali di abaikan oleh pihak sekolah dengan alasan keterbatasan Sumber daya manusia atau teknologi yang kurang memadai.

Dengan adanya Proxy server diharapkan jaringan yang ada di sekolah lebih optimal dan lebih terawasi sehingga pengguna bisa lebih nyaman dalam menggunakan fasilitas internet, selain itu bisa untuk mengontrol konten-konten negatif. Dengan pertimbangan dari permasalahan dan pencegahan guna pemanfaatan teknologi internet sehat maka sangat diperlukannya adanya sebuah alat atau sistem yang mengontrol itu semua yaitu perlu dibuatkannya Proxy server.

\section{TINJUAN PUSTAKA \\ 2.1 Pengertian internet}

Internet merupakan jaringan komputer yang di bentuk oleh departemen pertahanan Amerika Serikat pada tahun 1969, melalui proyek ARPA yang disebut ARPANET (Advanced Research Project Agency Network), [4] dimana komunikasi ini terhubung dengan jarak jauh. Pada mulanya ARPNET hanya menghubungkan 4 situs saja yaitu Stanford Research Institute, University of California, Santa Barbara, dan University of Utah [5]. Mereka membentuk suatu jaringan terpadu pada tahun 1969 dan secara umum ARPANET diperkenalkan pada Oktober 1972, tidak lama kemudian proyek ini berkembang pesat di seluruh daerah dan semua universitas di negara tersebut ingin bergabung sehingga ARPANET kesulitan untuk mengaturnya, oleh karena itu ARPANET dipecah menjadi dua bagian yaitu "MINET" untuk keperluan militer dan "ARPANET" untuk keperluan non-militer seperti universitasuniversitas. Gabungan dari kedua tersebut akhirnya dikenal dengan nama DARPA Internet yang kemudian disederhanakan menjadi Internet [6].

\subsection{Proxy}

Proxy server adalah sebuah server atau program komputer yang berperan sebagai penghubung antara komputer dengan jaringan internet.

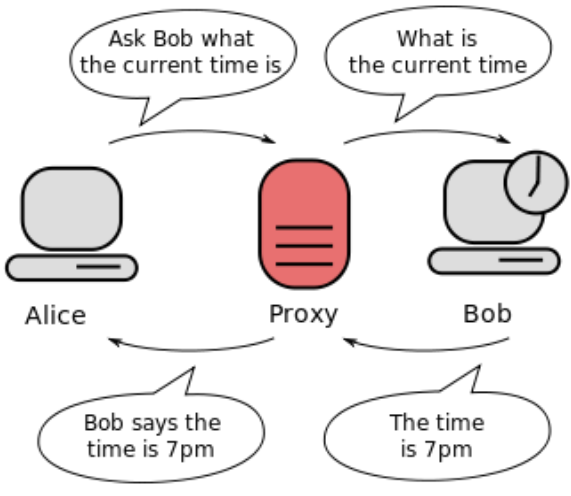

Gambar 1. Rangkaian Proxy Server

Konsep utama dari Proxy adalah Proxy merupakan pihak ketiga yang berdiri ditengah-tengah antara kedua pihak yang saling berhubungan dan berfungsi sebagai perantara, secara prinsip pihak pertama dan pihak kedua tidak secara langsung berhubungan, akan tetapi masing-masing berhubungan dengan perantara, yaitu Proxy. Proxy sendiri memiliki fungsi yaitu Connection Sharing, Filtering, Caching. 
Connection Sharing adalah Konsep dasar Connection Sharing pengguna tidak langsung berhubungan dengan jaringan luar atau internet, tetapi harus melewati suatu Gateway, yang bertindak sebagai batas antara jaringan lokal dan jaringan luar. Gateway ini sangat penting, karena jaringan lokal harus dapat dilindungi dengan baik dari bahaya yang mungkin berasal dari internet, dan hal tersebut akan sulit dilakukan bila tidak ada garis batas yang jelas jaringan lokal dan internet. Gateway juga bertindak sebagai titik di mana sejumlah koneksi dari pengguna lokal akan terhubung kepadanya, dan suatu koneksi ke jaringan luar juga terhubung kepadanya. Dengan demikian, koneksi dari jaringan lokal ke internet akan menggunakan sambungan yang dimiliki oleh gateway secara bersama-sama (connection sharing). Dalam hal ini, gateway adalah juga sebagai Proxy server, karena menyediakan layanan sebagai perantara antara jaringan lokal dan jaringan luar atau internet.

Filtering Bekerja pada layer aplikasi sehingga berfungsi sebagai firewall packet filtering yang digunakan untuk melindungi jaringan lokal dari serangan atau gangguan yang berasal dari jaringan internet, Filtering juga berfungsi melakukan filtering atas paket yang lewat dari jaringan yang terhubung serta untuk menolak akses ke situs web tertentu pada waktu-waktu tertentu.

Caching adalah Proxy server memiliki mekanisme penyimpanan obyek-obyek yang sudah pernah diminta dari server-server di internet, proses tersebut dinamakan cache server. Mekanisme caching akan menyimpan obyek-obyek yang merupakan hasil permintaan dari para pengguna, yang didapat dari internet

\subsection{Squid Proxy}

Squid merupakan daemon yang digunakan sebagai Proxy server dan web cache. Squid memiliki banyak kegunaan mulai dari mempercepat server web, caching DNS, caching situs, dan caching pencarian. Meskipun sering digunakan untuk protocol HTTP dan FTP, squid juga bisa melayani protocol lain seperti Transport Layer Security (TLS), Secure Sockets Layer (SSL), Internet Gopher, dan HTTPS.

\subsection{SARG}

SARG adalah tools open source yang memungkinkan sobat untuk menganalisis file log squid atau proxy dan menghasilkan laporan yang indah dalam format HTML dengan informasi tentang pengguna, alamat IP, situs diakses atas, total penggunaan bandwidth, waktu berlalu, download, akses ditolak website, laporan harian, laporan mingguan dan laporan bulanan.[7].

\section{METODE PENELITIAN}

Di dalam melakukan penelitian ini, dilakukan caracara pengumpulan data berupa teknik Studi Pustaka dan Observasi. Alasan peneliti melakukan metode ini adalah untuk menyajikan gambaran perilaku atau kejadian, untuk menjawab pertanyaan, dan untuk evaluasi yaitu melakukan pengukuran terhadap aspek tertentu melakukan umpan balik terhadap pengukuran tersebut sebagai berikut:

\subsection{Observasi}

Observasi partisipatif adalah Metode pengumpulan data yang digunakan untuk menghimpun data penelitian melalui pengamatan dan pengindraan di mana observasi atau peneliti benar-benar terlibat dalam keseharian responden.

Observasi terus terang atau tersamar yaitu Dalam hal ini, peneliti dalam melakukan pengumpulan data menyatakan terus terang kepada sumber data, bahwa ia akan melakukan penelitian, sehingga mereka yang diteliti mengetahui sejak awal sampai akhir tentang aktivitas si Peneliti.

Observasi tak berstruktur yaitu Observasi yang dilakukan tanpa menggunakan guide observasi. Pada observasi ini peneliti atau pengamat harus mampu mengembangkan daya pengamatannya dalam mengamati suatu objek.

\subsection{Topologi Jaringan}

Topologi jaringan yang digunakan dalam penelitian ini adalah sebagai berikut:

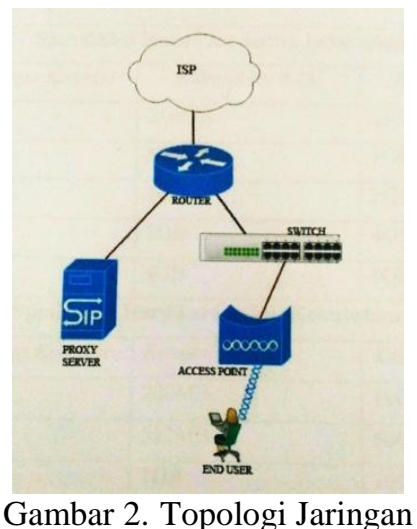

Gambar 2. Topologi Jaringan 


\section{IMPLEMENTASI}

Dalam melakukan penelitian ini, dimulai dari proses instalasi Squid terlebih dulu kemudian konfigurasi Squid dan SARG. Setelah semua di konfigurasi baru dilakukan tahap pengecekan proxy dan hasil dari pemasangan proxy.

\subsection{Instalasi}

\section{Instalasi Squid}

Willy: willypermanaputra $\$$ sudo apt-get install squid3

\section{Konfigurasi Squid}

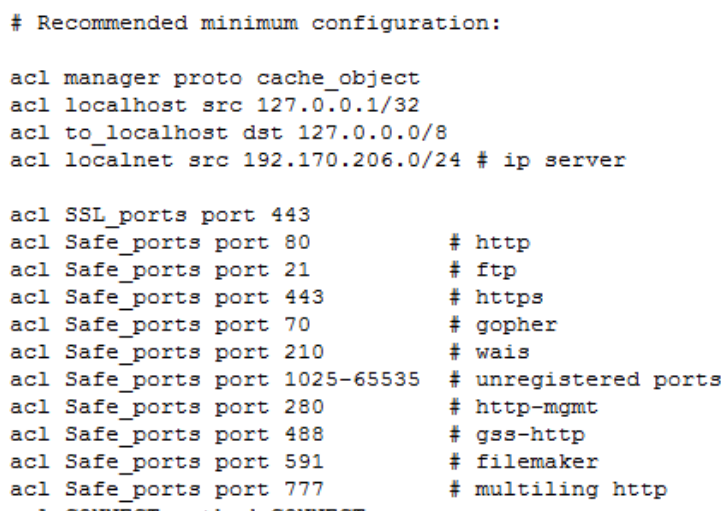

\section{Konfigurasi ACL}

acl bloksitus dstdomain. facebook.com . youtube.com

\section{Mengalihkan Port}

iptables -t nat -A PREROUTING -j REDIRECT -p tcp --dport 80 --to-ports 3128

\subsection{Testing}

Pada tahapan ini yaitu menguji proxy terhadap pengguna dapat kita lihat pemakaian proxy internet.

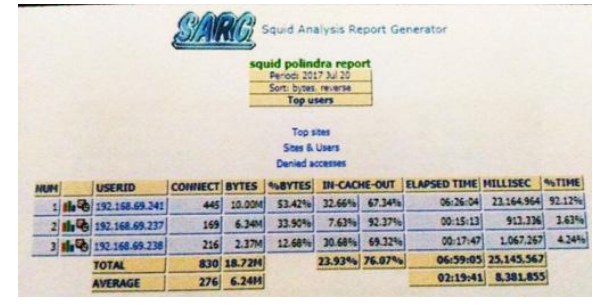

(a)

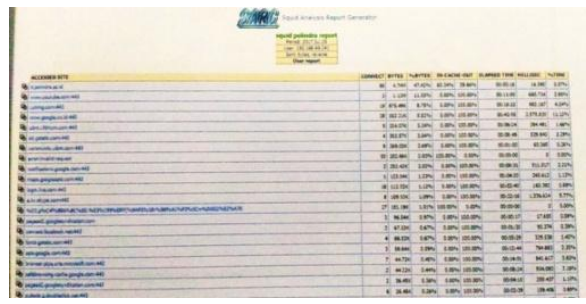

Gambar 3. Hasil pengujian Proxy (a) dan (b)

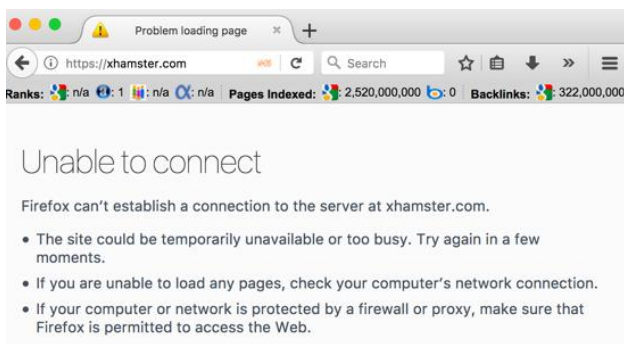

Try Again

Gambar 4. Situs Terblokir

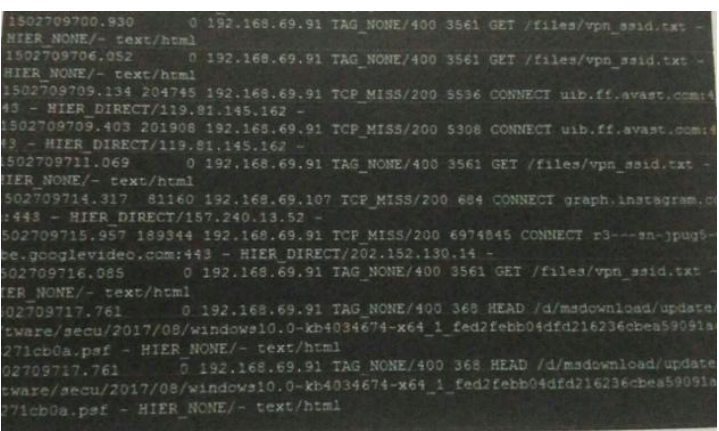

Gambar 5. Log Proxy

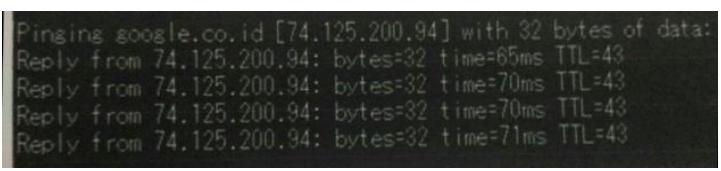

(c)

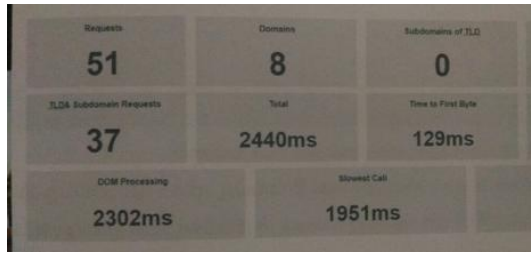

(d)

Gambar 5. Kecepatan Akses Sebelum di Proxy (c) dan (d)

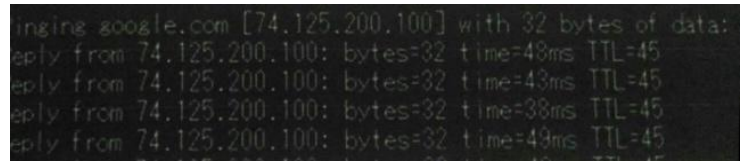

(e) 
Universitas AL Asyariah Mandar

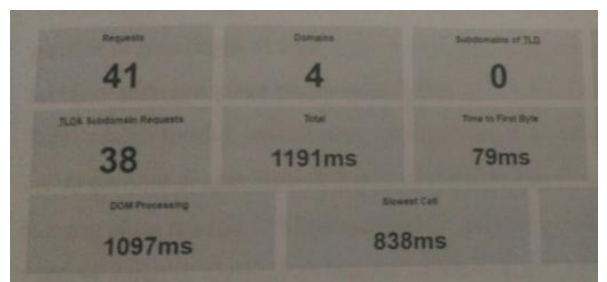

(f)

Gambar 6. Kecepatan Akses Setelah di Proxy (e) dan (f)

\section{KESIMPULAN}

Dilihat dari hasil pengujian di atas dapat di simpulkan bahwa pemakaian Proxy dapat mempercepat koneksi dan dapat membatasi akses konten negatif serta dapat kita lihat user atau pengguna telah membuka situs apa saja

\section{DAFTAR PUSTAKA}

[1] Umeshchandra, T. K., Ramjibhai, P. C.,"Improve Squid Proxy's Performance Using New Cache Replacement Architecture," IJMIE, vol. 2, no. 7, hal. 418-431, Juli 2012.

[2] Tsui, K.C., Kaiser, M.J., Liu, J., "Distributed Proxy Server Management: A Self-Organized Approach," Kluwer Academic Publisher, hal. 2, Sept. 2013.

[3] Saini, kulbir. 2001. Squid Proxy Server 3.1: Beginner's Guide. Birmingham. PACKT Publishing.

[4] Doug Engelbart's Role in ARPANET History". 2008. Retrieved 3 September 2009

[5] IEEE Recognizes SRI International for its Role in 1969 ARPANET

Transmission, https://www.sri.com/newsroom/press-releases/ieeerecognizes-sri-international-its-role-1969-arpanettransmission

[6] Bill Stewart, januari 2000, https://www.livinginternet.com/tabout.htm

[7] SARG Squid Analysis Report Generator, "https://opinikoe.com/sarg-squid-analysis-reportgenerator/" 